\title{
Housing First and the primary health care approach to health-equity
}

\section{Thilina Bandara}

\section{University of Saskatchewan}

Health is dependent on many factors outside of the traditional notions of doctors, hospitals and prescriptions. Housing status is one of the social determinants of health that has been shown to play a part in why some people have a poorer health status than others. ${ }^{1}$ Homelessness costs Canadians an estimated 7.05 billion dollars, with over 30,000 people without a home on any given night. ${ }^{2}$ In general, the gradients that exist within social determinants are leading to health inequities, where those people with a higher socio-economic status are healthier than those living in poorer conditions.

\section{Primary Health Care:}

The Primary Health Care (PHC) approach requires researchers, programmers and policy-makers to think more holistically when attempting to improve the overall health status of society by considering services that address these larger-scale social determinants necessary to create a healthier society. ${ }^{3}$ Simply put, PHC is "about creating the conditions that support health and wellness" ${ }^{\prime \prime}$ and the employment of "health-equity producing social policies." Connecting those in poverty to integrated healthcare services is therefore paramount in creating a successful PHC strategy.

\section{Housing First:}

Housing First is promising example of a PHC-inspired and health equity promoting social program that can improve the health status of vulnerable populations. First implemented in New York City by the Pathways to Housing in the early 90s, Housing First is a housing program that emphasizes access to housing as a basic right. In practice, this means that an agency following a Housing First program provides housing to homeless individuals, particularly to those with mental health and addictions issues, regardless of clients' sobriety or compliance to treatment. ${ }^{6}$ Central to
Housing First is a multi-disciplinary approach to supporting client needs. Teams consisting of social workers, nurses, counsellors, primary health physicians, and support staff manage clients and support them through day-to-day living. The team provides treatment services only when needed, as dictated by the client. ${ }^{7}$

Holding true to PHC principles, Housing First initiatives require partnership across many organizations and levels of institutions, including a commitment to both social service support as well as PHC integration. A recent evaluation of five Housing First sites in Canada showed that participants' have experienced high-quality support services (access to psychiatrists and primary care physicians, employment, cooking and grocery shopping) in a client-centred approach were critical to the program's success. Many of the Housing First sites have taken advantage of the initiative to partner with not only primary care hospital staff, but with community groups, mental health care organizations, the United Way and local businesses. ${ }^{7}$ When properly administered, the integrative approach to client support in Housing First can create the aforementioned healthfacilitative conditions within a vulnerable population.

Housing First also helps clients live more productive, healthier lifestyles. With regards to clients' interactions with police, welfare and health institutions (public system usage), Housing First clients have significantly fewer police interactions, incarcerations, hospital stays, emergency medical services uses and emergency room visits for primary care needs than homeless individuals not involved in the program. In a randomized control trial in New York, Housing First clients showed long term housing stability (24 months) and spent less time homeless than those without the program. ${ }^{5}$ Along with these improvements, the Housing First approach has also shown cost-saving potential; in Calgary, Alberta for example, the Housing First program yields 2.5 million dollar savings per year. ${ }^{8}$ These 
individual and societal wellbeing improvements as a result of Housing First represent the fulfillment of PHC goals and provide the basis for overall poverty-reduction in Canada.

\section{Conclusion:}

Primary Health Care is a worldview that stresses the importance of promotion and the sustainability of health for all. With growing evidence of its health and societal benefits, the Housing First approach represents a move towards a holistic paradigm for health service delivery. Housing First is essential to Canada's plan for improving the health of its population, and is being continually evaluated to optimize its implementation in the future. ${ }^{9}$ Early evaluations indicate that in order to achieve optimal implementation, programmers and policy-makers must tailor the size, scope and services to address the specific local homeless population needs. ${ }^{10}$ For now, it is imperative that health equity continues to be a goal of researchers, programmers and policy makers if we are to fulfill a truly healthy society. By bringing appropriate patient-centred health and wellness services to clients, while simultaneously addressing their basic need for housing, Housing First is a model for what PHC can look like in the real world.

\section{References}

1. Banbra C, Gibson M, Sowden A, Wright K, Whitehead M, Petticrew M. Tackling the wider social determinants of health and health inequalities: evidence from systematic reviews. J Epidemiol Community Health. 2010;64(6):284-91.

2. Gaetz S, Donaldson J, Richter T, Gulliver T. The state of homelessness in Canada 2013. Toronto: Canadian Homelessness Research Network Press. 2013. Available from: http://www.homelesshub.ca/ResourceFiles/ SOHC2103.pdf

3. Health Canada. Primary Health Care [homepage on the internet]. 2013. Available from: http://www.hc-sc.gc.ca/hcs-sss/prim/index-eng.php

4. Canadian Nurses Association. Primary Health Care [homepage on the internet]. 2014. Available from: http://www.cna-aiic.ca/en/on-the-issues/ better-health/primary-health-care

5. Starfield B. Politics, primary healthcare and health: was Virchow right? J Epidemiol Community Health. 2011;65(8):653-5.

6. Dunn JR, van der Meulen E, O'Campo P, Muntaner C. Improving health equity through theory-informed evaluations: a look at housing first strategies, cross-sectoral health programs, and prostitution policy. Eval Program Plann. 2013;36:184-90.

7. Nelson G, Rae J, Townley G, Goering P, Macnaughton E, Piat M, et al. Implementation and fidelity evaluation of the Mental Health Commission of Canada's At Home/Chez Soi Project: cross-site report. 2012. Available from: http://www.mentalhealthcommission.ca/English/system/files/private/ document/Housing_At_Home_Qualitative_Report_Implementation Fidelity_Cross_Site_ENG.pdf

8. Calgary Homeless Foundation. Annual General Meeting. [online]. 2013. Available from: http://media3.marketwire.com/docs/917chf r.pdf

9. Government of Canada. Harper Government supports Housing First model to reduce homelessness. 2013. Available from: http://news.gc.ca/web/ article-en.do?nid=785229

10. Keller C, Goering P, Hume C, Macnaughton E, O'Campo P, Sarang A, et al. Initial implementation of Housing First in Five Canadian Cities: how do you make the shoe fit, when one size does not fit all? Am J Psychiatr Rehabil. 2013;16(4):275-89.

\section{Thilina Bandara}

Thilina Bandara is a PhD student and Natural Sciences and Engineering Research Council fellow in the Department of Community Health and Epidemiology at the University of Saskatchewan. He is also currently a part of the Healthy Children Team and Saskatchewan Equity Study at the Saskatchewan Population Health and Evaluation Research Unit. His research interests include health equity, knowledge translation and One Health. 